\title{
HyGenSys: a Flexible Process for Hydrogen and Power Production with Reduction of $\mathrm{CO}_{2}$ Emission
}

\author{
F. Giroudière', J.L. Ambrosino', B. Fischer', D. Pavone', E. Sanz-Garcia', \\ A. Le Gall'2, E. Soutif ${ }^{2}$ and H. Vleeming ${ }^{3}$ \\ 1 IFP Energies nouvelles-Lyon, Rond-point de l'échangeur de Solaize, BP 3, 69360 Solaize - France \\ 2 Technip, 92973 Paris La Défense Cedex - France \\ 3 PDC, P.O. Box 7052, 4800 GB Breda - The Netherlands \\ e-mail: fabrice.giroudiere@ifpenergiesnouvelles.fr - j-louis.ambrosino@ifpenergiesnouvelles.fr - beatrice.fischer@ifpenergiesnouvelles.fr \\ didier.pavone@ifpenergiesnouvelles.fr - elena.sanz-garcia@ifpenergiesnouvelles.fr - alegall@technip.com - esoutif@technip.com \\ vleeming@process-design-center.com
}

Résumé - HyGenSys : un procédé flexible de production d'hydrogène et d'électricité avec réduction des émissions de $\mathbf{C O}_{2}-$ Cet article présente les développements récents d'HyGenSys, nouvel éco-procédé de conversion du gaz naturel en hydrogène et électricité. Le concept combine un réacteur-échangeur spécifique de reformage à la vapeur avec une turbine à gaz. En fait, la chaleur nécessaire pour la réaction de reformage à la vapeur provient des fumées pressurisées produites dans une turbine à gaz au lieu d'un four conventionnel. Grâce à cette intégration thermique poussée, l'efficacité globale est améliorée et la consommation de gaz naturel réduite, ce qui représente un avantage d'un point de vue économique et environnemental notamment vis-à-vis de la réduction des émissions de $\mathrm{CO}_{2}$.

Deux déclinaisons du procédé sont détaillées, elles répondent chacune à des besoins différents. La première, appelée HyGenSys-0, correspond à la production d'hydrogène pour le raffinage et la pétrochimique. La deuxième, appelée HyGenSys-1, permet la production d'énergie centralisée avec la capture de $\mathrm{CO}_{2}$ en précombustion. Dans ce cas, l'hydrogène produit est entièrement utilisé pour alimenter une turbine de production d'électricité. HyGenSys-1 a été développé et optimisé au cours du projet CACHET, financé par la Communauté européenne, avec comme objectif de fournir une puissance de 400 MW minimum.

Les versions HyGenSys-0 et HyGenSys-1 du procédé sont décrites en détail avec les défis et avantages comparés aux technologies existantes. Dans les deux cas, le cœur de la technologie est le réacteuréchangeur dont le développement est également présenté en détail. La conception de réacteur-échangeur est basée sur un arrangement innovant de tubes à baïonnette autorisant une conception à grande échelle, de l'échange thermique multiple entre la fumée pressurisée chaude, l'alimentation de gaz naturel et l'effluent riche en hydrogène.

Abstract - HyGenSys: a Flexible Process for Hydrogen and Power Production with Reduction of $\mathrm{CO}_{2}$ Emission - This paper presents the latest development of HyGenSys, a new sustainable process and technology for the conversion of natural gas to hydrogen and power. The concept combines a specific steam reforming reactor-exchanger with a gas turbine. The heat necessary for the steam reforming reaction comes from hot pressurized flue gases produced in a gas turbine instead of a conventional furnace. Thanks to this high level of heat integration, the overall efficiency is improved and the natural 
gas consumption is reduced which represents an advantage with regard to economics and $\mathrm{CO}_{2}$ emission reduction. In addition to the efficient HyGenSys process scheme itself, the technology of the reactorexchanger also offers a high level of heat integration for even more energy saving.

Two main alternatives are examined in order to meet two different requirements. The first one, named HyGenSys-0, focuses on the hydrogen production for the refining and petrochemical application. The second one named HyGenSys-1, concerns the centralized power production with pre-combustion $\mathrm{CO}_{2}$ capture. In that case, the produced hydrogen is fully used to fuel a power gas turbine. HyGenSys-1 has been developed and optimised in CACHET, a European Community funded project. The CACHET electrical power objective was $400 \mathrm{MW}$ at the minimum.

HyGenSys-O and HyGenSys-1 are described in detail with challenges and advantages compared to existing technologies.

For both alternatives, the heart of the technology is the reactor-exchanger. The reactor-exchanger design relies on an innovative arrangement of bayonet tubes that allows, at large scale, multiple heat exchanges between hot pressurized flue gas, natural gas feed and hydrogen rich stream produced.

\section{INTRODUCTION}

Nowadays, there are several options for meeting the growing hydrogen needs. The most common hydrogen production technology is steam reforming which can handle a variety of feedstocks including natural gas, LPG and naphtha. Autothermal reforming or partial oxidation reactors could also be used but these two processes lead to higher $\mathrm{CO}_{2}$ emission because of the energy consumption of the air separation unit necessary for oxygen production.

Steam Methane Reformers (SMR) are based on very mature technologies and are offered by a number of licensors such as Foster Wheeler Corp., Haldor Topsoe AS, Technip, Lurgi, and Uhde. However SMRs are large and expensive to construct mainly because of the large fire box that is required to avoid tube damage by very hot flames and the upper convection section that recover heat by steam generation. Another conventional SMR constraint is the need to generate and valorise huge amount of steam on site.

This technical paper aims at exploring the challenges and advantages of an innovative steam reforming process called HyGenSys and associated reactor-exchanger. HyGenSys is a " $\mathrm{CO}_{2}$ ready" co-generation process (hydrogen production through steam reforming reactions and power generation with facilitated $\mathrm{CO}_{2}$ capture for sequestration). It is developed by IFP Energies nouvelles [1] and within the European CACHET project (carbon dioxide capture and hydrogen production from gaseous fuels) $[2,3]$.

\section{HYGENSYS CONCEPT}

The HyGenSys process is a HYdrogen GENeration SYStem that comprises a steam methane reformer coupled with a gas turbine. The energy necessary for natural gas reforming is supplied by convective exchange involving the hot flue gas leaving the gas turbine. The main characteristics of the process are a very high degree of heat integration and consequently a reduction of $\mathrm{CO}_{2}$ emission.

\subsection{Description of the Reaction}

The objective of steam methane reforming process is to maximise the quantity of hydrogen produced. The synthesis gas can either be used by refining and petrochemical applications or by power generation plants.

The feedstock used here is natural gas, the two mains reactions are the steam reforming reaction (1) and the water gas shift reaction (2):

$$
\begin{gathered}
\mathrm{CH}_{4}+\mathrm{H}_{2} \mathrm{O} \Leftrightarrow \mathrm{CO}+3 \mathrm{H}_{2} \\
\mathrm{CO}+\mathrm{H}_{2} \mathrm{O} \Leftrightarrow \mathrm{CO}_{2}+\mathrm{H}_{2}
\end{gathered}
$$

The steam methane reforming reaction (1) is strongly endothermic; the hydrogen formation is promoted by low pressure and high temperature, these reactions occurs only in the steam reforming reactor. In order to minimize the quantity of unconverted methane, called methane slip, the outlet temperature of steam reforming is chosen as high as possible, that is more or less $900^{\circ} \mathrm{C}$ due to material constraint. The water gas shift reaction (2) is exothermic and thermodynamically favoured by low temperature, whereas pressure has no influence.

\subsection{Description of Conventional Combined Cycle Gas-Turbine}

To understand the process concept, let's come back to the principle of gas turbine. In a gas turbine the air is compressed in an axial compressor up to a high level of pressure (between 10 to 30 bar abs typically), then heated by combustion of fuel in the combustion chamber. Fuel can be natural gas or any suitable fuel like hydrogen rich gas. Flue gases are expanded through a turbine down to atmospheric pressure. This turbine is driving the air compressor and a power generator. The aim of the turbine is to extract the energy from the gas at the outlet of the combustion chamber at high-pressure, 


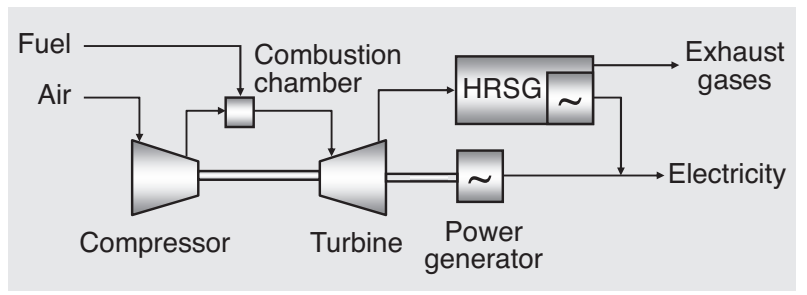

Figure 1

Simplified combined cycle gas turbine scheme.

high-temperature. Some gas turbines have two shafts: the turbine is then split in two parts; the first part of the turbine is driving the air compressor, the second part the power generator.

Figure 1 presents a standard combined cycle gas turbine scheme. The flue gas leaving the turbine is still hot and Heat Recovery Steam Generation unit (HRSG) allows steam generation. In a combined cycle scheme, the steam is expanded in steam turbines to produce additional power.

Figure 2 (Siemens courtesy) is an illustration of existing gas turbine technology.

For the HyGenSys scheme, existing gas turbine (SGT-700 for example) will be modified in order to split the second part of the actual turbine and optionally, for $\mathrm{CO}_{2}$ concern, to use hydrogen rich fuel instead of natural gas.

\subsection{HyGenSys Concept}

In HyGenSys process depicted in Figure 3, the steam reforming reactions are achieved within a reactor-exchanger. The reforming heat is provided to this reactor by the hot pressurized flue gas leaving the first part of this turbine at an intermediate level of pressure (about 3-5 bara). This flue gas has been reheated at about $1300^{\circ} \mathrm{C}$ in a secondary combustion chamber prior to entering the reactor-exchanger shell. The temperature of about $1300^{\circ} \mathrm{C}$ is the result of a compromise between process heat balance and reactor design criteria. At the outlet of the reactor-exchanger shell, the flue gas is again reheated before entering the expander that generates power.

There are three main challenges for this new process:

- split gas turbine (only the first shaft is used);

- hydrogen combustion in the gas turbine combustion chambers (proven up to $50 \%$ hydrogen, potentially possible up to $75 \%$ or higher);

- reactor-exchanger challenge: operation up to $900^{\circ} \mathrm{C}$ with hot flue gases at $1300^{\circ} \mathrm{C}$.

\section{HYGENSYS PROCESSES}

Two main alternatives are examined in order to meet two different requirements. The first one, named HyGenSys-0, focus on the hydrogen production for the refining and petrochemical application. The second one named HyGenSys-1, concerns the centralized power production with pre-combustion $\mathrm{CO}_{2}$ capture.

\subsection{HyGenSys-0 Hydrogen Production for the Refining and Petrochemical Application}

\subsubsection{HyGenSys-0 Process Description}

The hot desulfurized natural gas is mixed with steam and injected in the SMR reactor-exchanger (Fig. 4). For the

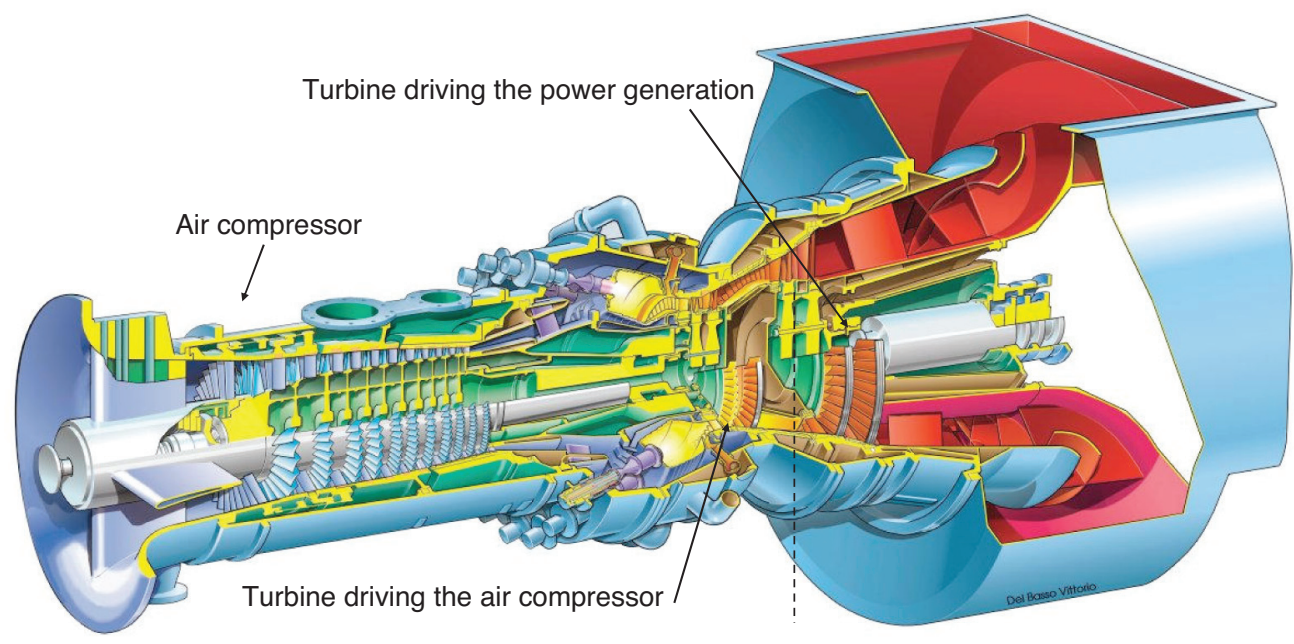

Figure 2

SGT-700 Core Engine (dashed line: transition between the two parts of the turbine). 


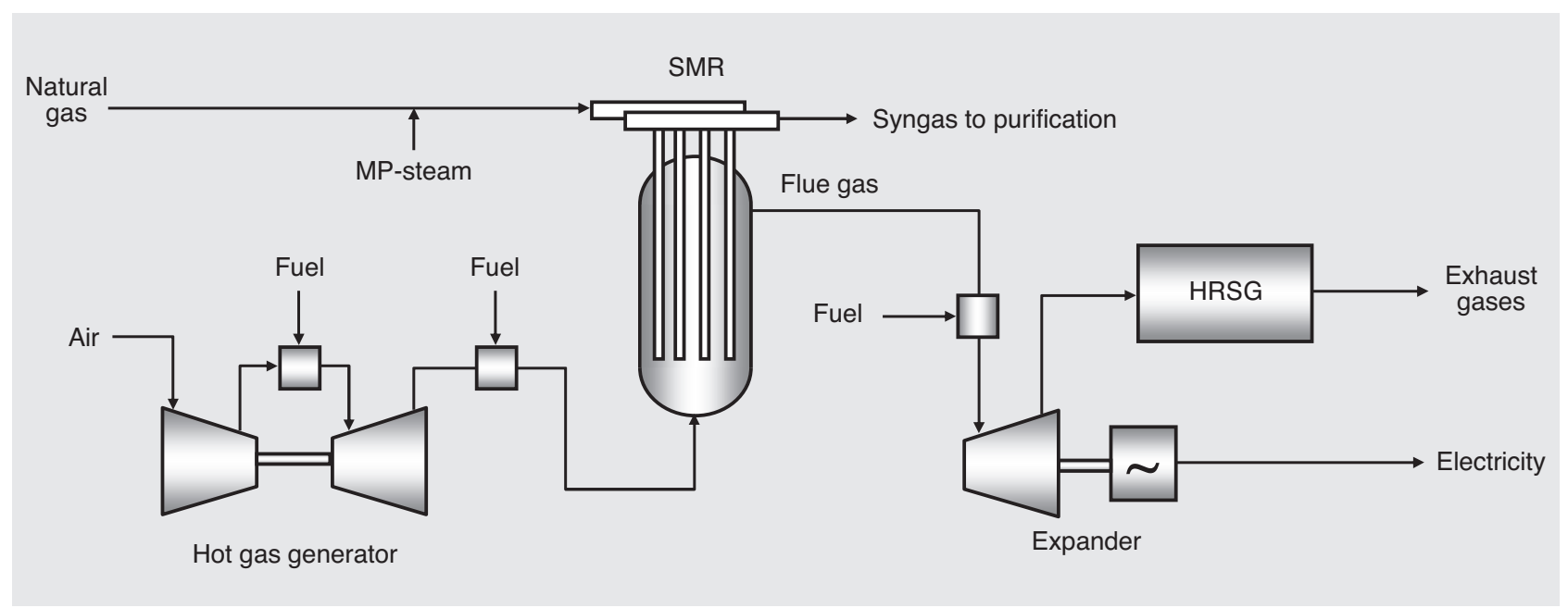

Figure 3

Principle of HyGenSys process: heat of reaction provided by hot pressurized gases.

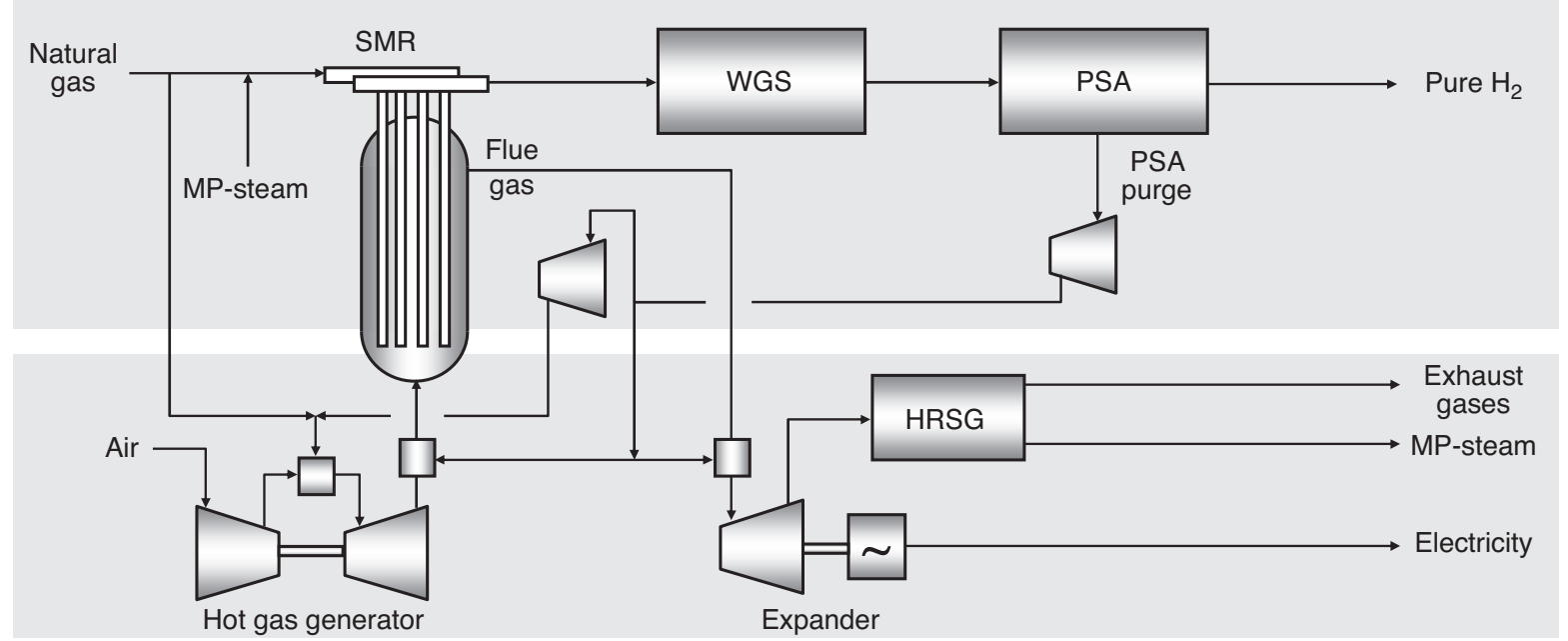

Figure 4

Schematic representation of HyGenSys-0.

current design the steam to carbon ratio $(S / C)$ was fixed at 2.7, which is regarded as the operating minimum value to prevent coke formation and metal dusting in the preheating and reforming sections.

Reforming takes place in the bayonet tube of HyGenSys heat exchanger reactor over a reformer catalyst. The reactor operates at about 25 bara with a catalyst bed outlet of $900^{\circ} \mathrm{C}$. The syngas is cooled against high pressure steam generation. A high temperature water gas shift converts the carbon monoxide with steam to additional molecules of hydrogen and carbon dioxide. After cooling, the syngas feeds a pres- sure swing adsorption unit in order to recover hydrogen; the purge gas still contains hydrogen at low pressure. A two stage compressor sends the purge gas to the hot gas generation section, where it's burned. The hot generation section provides hot flue gas to SMR reactor-exchanger and produces power. Air is compressed up to 18 bar using modified turbine SGT-700 allowing use of hydrogen rich fuel in the combustion chamber. The flue gas resulting from this combustion is at about $1140^{\circ} \mathrm{C}$ (result from simplified process simulation) and is expanded to about 4.5 bara, this step provides enough power to drive the compressor of the turbine. The flue gas is then reheated in a secondary combustion 
chamber with hydrogen rich fuel to increase the temperature to about $1300^{\circ} \mathrm{C}$. The high-temperature flue gas is used to heat the SMR reactor-exchanger. It is then reheated in a third combustion chamber using hydrogen rich fuel from the PSA purge. The gas is then expanded over Dresser Rand FCCkind expander down close to atmospheric pressure, to generate electric power. This expander can accept flue gas up to $760^{\circ} \mathrm{C}$. This temperature has been chosen to maximize the power production.

The Heat Recovery Steam Generation (HRSG) section recovers heat from the flue gas and produces MP steam for SMR, the little amount of extra steam is exported. The flue gas in HRSG is also used to preheat the natural gas.

\subsubsection{HyGenSys-0 Process Results}

The production of $100000 \mathrm{Nm}^{3} / \mathrm{h}$ of hydrogen requires about $32.6 \mathrm{t} / \mathrm{h}$ of natural gas with one modified turbine SGT-700 adapted for combustion of blend of natural gas and part of the PSA purge. Thanks to the expander, in addition to the hydrogen, the unit also generates 30.2 MW of electricity. The HRSG section produces medium pressure steam at about 40 bars that is mainly used internally for the SMR reaction (about $75.4 \mathrm{t} / \mathrm{h}$ for an $S / C$ ratio of 2.7 ). With HyGenSys process the extra stream production that needs to be exported is minimized (only $18.6 \mathrm{t} / \mathrm{h}$ ).

In comparison, a standard SMR producing the same hydrogen flow with about the same natural gas feed flow, would not produce electrical power but a huge amount of steam that needs to be exported. Depending upon plant location steam is not always valuable. For a site with net demand of electricity, electric power can also be produced by steam turbine, but in this case the efficiency would be less than a direct transformation of flue gas energy with an expander like the one used in HyGenSys process.

As explained above the main difference of HyGenSys with a standard SMR lies in the flue gas side. As for the process side, except the reactor-exchanger itself, the downstream purification steps remain the same: water gas shift and pressure swing adsorption to get pure hydrogen.

\subsection{HyGenSys-1 for Centralized Power Production}

HyGenSys-1 has been developed and optimised during CACHET Project [4] funded by the European Community, with an electrical power objective of $400 \mathrm{MW}$ minimum.

\subsubsection{Base Case and Reference Case}

In order to compare four pre-combustion capture technologies identified as promising, a methodology alignment has been defined. Hence, a baseline was studied for the design and cost estimate of a combined hydrogen and power production facility. Two cases, named "Reference Case" and "Base Case", were selected. For results comparison this paper will focus on the HyGenSys process.
The Reference Case produces about 400 MW (net) and corresponds to a classical technology without $\mathrm{CO}_{2}$ capture. A Combined Cycle Gas Turbine (CCGT) is selected to produce electricity without any $\mathrm{CO}_{2}$ captured or hydrogen production. This Reference Case has been set by NTUA (National Technical University of Athena) in close cooperation with Siemens and other partners.

The state-of-the-art technology for $\mathrm{CO}_{2}$-capture is called the Base Case. The technologies used in this process are Auto Thermal Reforming (ATR) with a CO-shift reactor and a $\mathrm{CO}_{2}$-absorber.

The target for technologies developed in the CACHET project is to avoid $90 \%$ of the carbon dioxide emission of the Reference Case that does not capture the $\mathrm{CO}_{2}$. Therefore the $\mathrm{CO}_{2}$ avoidance rate is calculated as shown in Equation (1) below:

Avoidance rate $=\frac{\left(\mathrm{CO}_{2 \mathrm{Ref}} / E_{\mathrm{Ref}}\right)-\left(\mathrm{CO}_{2 \mathrm{Case}} / E_{\text {Case }}\right)}{\left(\mathrm{CO}_{2 \mathrm{Ref}} / E_{\mathrm{Ref}}\right)} \cdot 100 \%$

with $\mathrm{CO}_{2 \text { Ref: }}: \mathrm{CO}_{2}$ emission to the air, without taking into account the $\mathrm{CO}_{2}$ in the air feed; $E$ : net power production; Ref: reference case, CCGT without $\mathrm{CO}_{2}$ capture; Case: specific case, for example HyGenSys-1, CCGT with $\mathrm{CO}_{2}$ capture.

Hereafter is presented a simplified description of the Base Case set by Technip in close cooperation with other partners. The Base Case process takes in account an available technology of air-blown Auto Thermal Reforming (ATR). In the ATR unit, reactions of partial oxidation and steam reforming take place. The inputs are preheated natural gas, steam and compressed air. The output is syngas. The syngas stream is treated in the high- and low-temperature (HT/LT) shift reactors to convert $\mathrm{CO}$ to $\mathrm{CO}_{2}$. The $\mathrm{CO}_{2}$ is then separated from the syngas by chemical absorption using an activated amine as solvent (MDEA) and finally compressed for export to storage $\left(\mathrm{CO}_{2}\right.$ capture). The hydrogen-rich stream is used as fuel for a gas turbine. The exhaust stream of the gas turbine goes into the Heat Recovery Steam Generation (HRSG) section, where steam and electricity are produced. The Base Case process is schematically represented in Figure 5.

\subsubsection{HyGenSys-1 Process}

The HyGenSys- 1 scheme is the direct application of the HyGenSys basic concept. Its optimisation focuses in particular on:

- the determination of the number of HyGenSys trains required to produce enough hydrogen fuel to feed the main gas turbine (SGT5-4000F);

- the optimisation of each HyGenSys train: hot gas generator selection, reactor-exchanger process specification, power recovery expander selection, heat recovery steam generation design; 


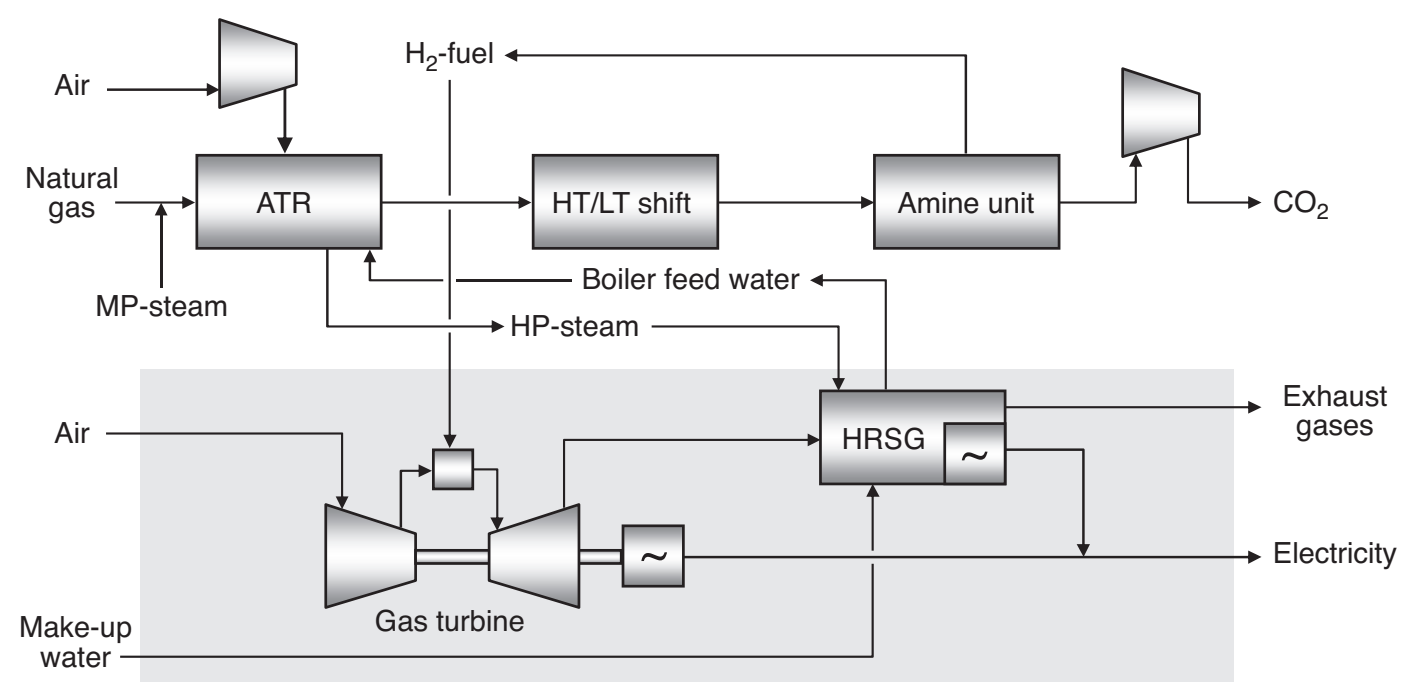

Figure 5

Schematic representation of the Base Case.

- the study of the influence of the operating parameters, such as, the steam to carbon ratio and the dilution rate of the hydrogen fuel with steam.

Simulation iterations integrating data from Siemens were necessary to determine the number of HyGenSys trains. The result is that three parallel HyGenSys trains are necessary: equipments that are implemented in parallel are represented with $\mathrm{A} / \mathrm{B} / \mathrm{C}$ in Figure 6.

When the steam to carbon ratio is increased, the HyGenSys-1 net efficiency logically decreases as the medium pressure steam is consumed by the process instead of being sent to steam turbines generating power. The net efficiency drops with about 3.5 points when steam over carbon ratio increases from 2.5 to 5 . The final choice considers a value of 2.7 which reflects on operational proven minimum value for natural gas steam reforming. This value prevents coking of the catalyst and metal dusting corrosion.

The pressure of the SMR is derived from the required pressure of hydrogen-rich fuel gas at the entrance of the combustion chamber of turbine (defined by gas turbine manufacturer) without recompression of hydrogen which is energy consuming and expensive.

The impact of hydrogen fuel dilution with steam is also investigated as the dilution is not favourable for the net efficiency of the global scheme. If technical developments are done on turbine burners' technology, a future dilution of $30 \%$, instead of $50 \%$ as assumed at present, could increase the efficiency by 1.5 point.

For pressure drops reasons and so energy loss, the implementation of a common HRSG to treat the flue gases leaving the FCC-kind expander and the large turbine was not feasible. Hence, a dedicated HRSG was used for each of them.

To summarize, HyGenSys- 1 presented in Figure 6 is a thermally integrated process with:

- three parallel HyGenSys heat-exchanger reactors, each one using a hot gas generator from Siemens (SGT-700) followed by an expander from Dresser-Rand (E-248) and a heat recovery steam generation system;

- the syngas produced is treated in high- and low-temperature water gas shift reactors;

- the $\mathrm{CO}_{2}$ is separated by an amine unit (activated MDEA) and compressed for storage;

- the hydrogen rich stream is partially used as fuel in a large turbine from Siemens SGT5-4000F (modified for hydrogen use), but also as feed for the different combustion chambers of the three parallel HyGenSys hot gas generators. Hydrogen-rich gas fuel is diluted with MP steam to produce a 50/50 mixture of fuel/inert at the turbine combustion chambers. This hydrogen dilution figure is coming from our Cachet partner Siemens. The idea is to use the existing gas turbine with minor modifications of the combustion chambers.

\subsubsection{Key Performances Data Process Comparison}

The CACHET objective of 400 MWe power generations is largely overreached with a total net power of $465.5 \mathrm{MWe}$ (Tab. 1).

Compared with the CACHET Base Case the net power production of HyGenSys-1 is $27 \%$ higher and the overall 


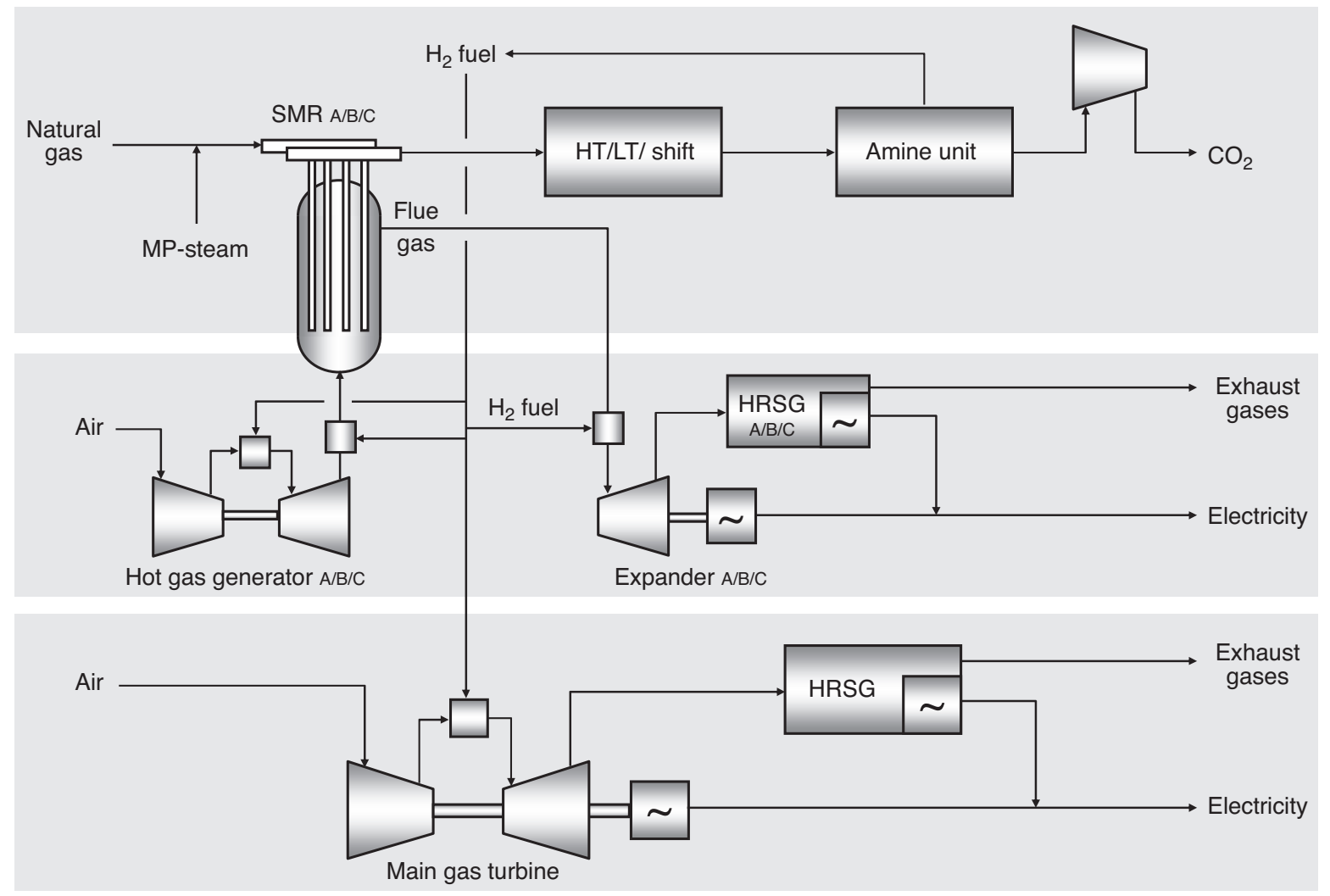

Figure 6

Schematic representation of HyGenSys-1.

TABLE 1

Key performance data of HyGenSys-1 compared with Base and Reference Cases

\begin{tabular}{l|c|c|c}
\hline & $\begin{array}{c}\text { Reference } \\
\text { Case }\end{array}$ & Base Case & HyGenSys-1 \\
\hline $\mathrm{H}_{2}$ production & no & ATR & SMR \\
\hline Capture $\mathrm{CO}_{2}$ & no & yes & yes \\
\hline Total net power output (MW) & 389.8 & 365.6 & 465.6 \\
\hline Overall efficiency & 57.2 & 40.9 & 44.1 \\
\hline $\mathrm{CO}_{2}$ capture rate $(\%)$ & 0.0 & 94.7 & 78.2 \\
\hline $\mathrm{CO}_{2}$ avoidance rate $(\%)$ & 0.0 & 92.6 & 71.2 \\
\hline $\mathrm{CO}_{2}$ captured cost $(€ /$ ton$)$ & & 82.1 & 83.9 \\
\hline $\mathrm{CO}_{2}$ avoided cost $(€ /$ ton) & & 117.5 & 118.4 \\
\hline $\mathrm{Cos}_{\text {of }}$ of electricity $(€ / \mathrm{MWh})$ & 47.5 & 86.6 & 78.0 \\
\hline
\end{tabular}

efficiency is about $8 \%$ higher. This result is reached thanks to the additional power generated by expansion of the hot exhaust gases leaving the flue gas side of HyGenSys reactorexchanger. The cost of electricity is $9 \%$ lower than the Base Case.
Capture rate and avoided rate are below CACHET target of $90 \%$, primarily resulting from the fact that due to thermodynamic equilibrium about $4 \%$ methane remains in the syngas. The methane passes the water gas shift and amine unit and stays with the $\mathrm{H}_{2}$-rich fuel, which is burned in the turbine combustion chamber without capture.

Two alternatives were examined in a previous article [3] in order to obtain higher level of capture rate.

\section{HYGENSYS REACTOR-EXCHANGER}

\subsection{Introduction of the Solution}

The steam reforming reaction is globally very endothermic. Furthermore, for thermodynamic reasons, a very high temperature is required to achieve the intended conversion of natural gas and steam into syngas. In conventional steam reforming units, the conversion is achieved in tubes filled with catalyst. Those tubes are heated in a furnace or less often by heat exchange with a hot stream such as an ATR effluent. However, these existing reactor concepts are not applicable to HyGenSys which relies on a devoted SMR 
reactor exchanger which shall ensure production of syngas and heat exchange with hot pressurized flue gas.

The HyGenSys reactor concept is based on a vertical arrangement of double pipes (also called bayonet tubes). In the bayonet tube concept, natural gas and steam are fed to the annular section which is filled with steam reforming catalyst. Bayonet tubes have already been used by Topsoe for steam methane reforming (Haldor Topsoe Convection Reformer) in the 1990's [5], but these steam reforming reactor is limited to small capacity units. The reactor uses a tube-sheet at high temperature with a large pressure drop. The tube-sheet becomes very thick when the reactor diameter is large.

The main innovation of the HyGenSys reactor is the specific arrangement of the bayonet tubes in the pressurized vessel, with external connections and no tube sheets. Thanks to this patented solution, there is in principle no size limitation in the reactor diameter [6].

The conversion of the feed into syngas is achieved in this annular section while the stream is being heated. The substantial heat required by the reaction is mainly supplied by heat exchange through the wall of the outer tube, thanks to a hot flue gas stream which flows in counter-current to the process side. The resulting hot syngas provides additional heat to the catalytic section while being routed back and cooled through the internal pipe.

Figure 7 shows the bayonet tube concept and the different flow streams.

The bayonet tubes are contained inside a pressurized and insulated shell (Fig. 8). The bundle of tubes is fixed to the reactor upper cap and hangs vertically. The catalyst loading, the feed distribution and the syngas collection are ensured because of an external manifold arrangement of the upper part of the bayonet tube. The inner tube passing through the external pipe avoids the use of tubesheets and allows the connections to be carried out outside the reactor shell. Each bayonet tube is inserted in a flue gas sheath (or chimney) as shown in Figure 7. The narrow section between the chimney walls and the bayonet outer tube restricts the hot flue gas around the bayonet tubes and induces high velocity. The high turbulence developed favours convective heat transfer to the catalyst.

\subsection{Constraints of the Reactor-Exchanger}

\subsubsection{HyGenSys Process Constraints}

The reactor-exchanger concept described above has been adapted to the HyGenSys process characteristics: its maximum capacity is limited by the flue gas flow rate that can be provided by the biggest Siemens two-shaft gas turbine (SGT-700) that will be used as hot gas generator. Therefore, the reactor shall work with both process side and heating side under pressure (process side operating pressure is chosen so that hydrogen can feed the turbine without any recompression). In addition, the pressure difference between process side and flue gas side is significant (about 30 bars). The reactor internals and tubes have to be suitable for the mechanical stress induced by such a pressure difference. As a consequence of these two points and for economical reasons, a compact arrangement of the reactor is desired.

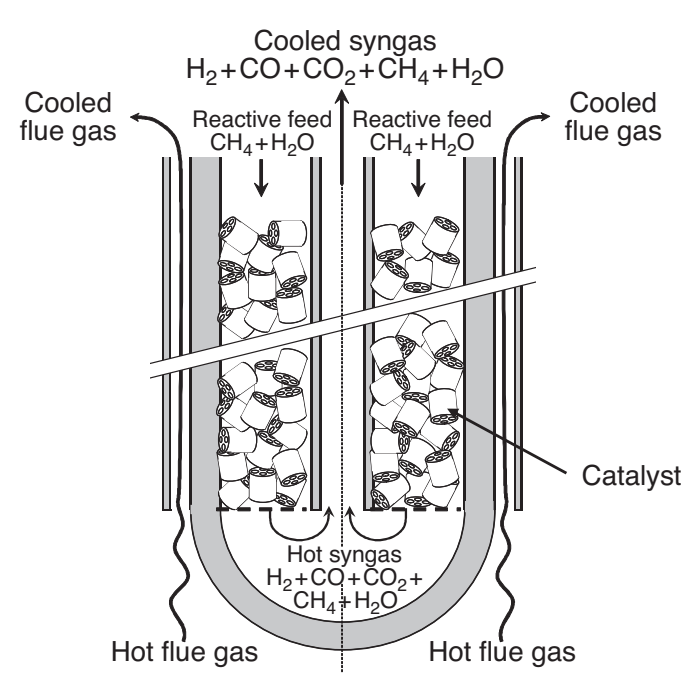

Figure 7

Bayonet tube concept.

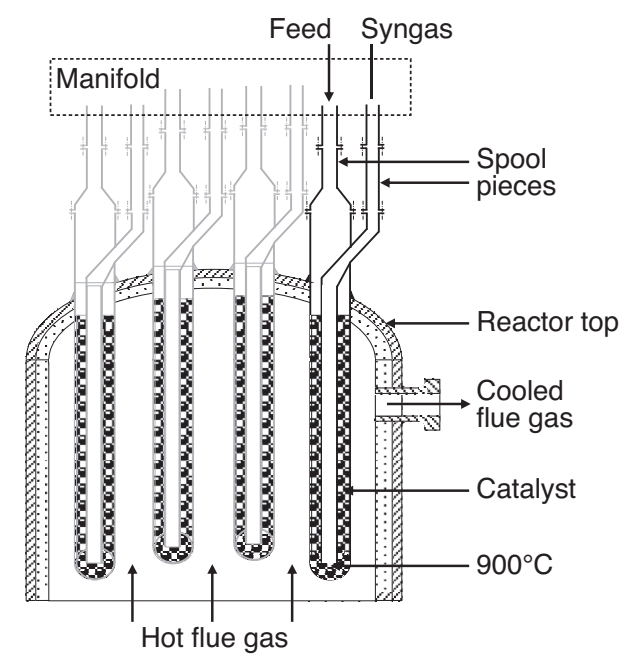

Figure 8

Reactor arrangement concept. 


\subsubsection{Material Constraints}

The extreme operating conditions inside the reactor lead to very high thermal and mechanical constraints (flue gas temperature can achieve values of about $1300^{\circ} \mathrm{C}$ ). The materials selection is then essential. Metals and alloys are generally susceptible to carbon attacks when exposed at high temperature to an environment containing mixtures of $\mathrm{CO}, \mathrm{H}_{2}$ and hydrocarbons. Carbon attack refers to the metal damaging due to coke deposition, carburization and metal dusting. These three phenomena act at different temperature ranges between 400 and $1000^{\circ} \mathrm{C}[7,8]$, so each one will be an issue for a different part of the metallic bayonet tube. Specific studies have been carried out to find the most adapted alloys for the design.

\subsubsection{Reliability and Operatibility}

As explained previously, methane conversion is favoured by high temperature. Anyway, the reactor operating conditions are limited in practice by the highest acceptable temperature allowed by existing alloys. Additionally, special attention must be paid in keeping reactor operation as steady and uniform as possible: reactor internals shall be prevented from temperature spots that may cause tube damage. Any leakage within the reactor would result in a self combustion of feed or product with the oxygen of the flue gas. Consequently, the reactor design must consider material testing of internals, leaks detection and replacement of any damaged parts to ensure safety and reliability.

Catalyst loading and unloading is also essential. Since no specific catalyst development was planned in the CACHET project, the reactor concept has to be compatible with commercial catalyst. This also applies to the process flow conditions across the catalyst pellets. Loading and un-loading operations of the bayonet tubes must be feasible and reproducible (uniform feed distribution through the tube and also between each tube).

An iterative work has been carried out to take into account all the factors described above, essentially to determine the optimum operation conditions, the materials selection, as well as the tubes and reactor geometry. Final results are presented and discussed in the next sections.

\subsection{Selection of Geometry and Materials}

Because of the chemical composition of the syngas which favours the metal dusting phenomenon, the material 602CA has been selected for the internal tube of the bayonet. As this tube is not under pressurised design conditions (about same pressure inside and outside the internal tube), only the strength due to its own weight has been checked.

With respect to the external tube, the very high temperature is obviously the main constraint with regard to creep strength for the material selection, associated with a corrosive environment. Therefore the external tube is made of several sections of Manaurite with different thicknesses with regard to the temperature variation. The external diameter is set constant to preserve a correct flue gas flow and then the catalytic space is more important for smaller thicknesses i.e. in the upper part of the bayonet (Fig. 9).

Finally, the flue gas sheaths also experience a very high temperature (up to $1300^{\circ} \mathrm{C}$ ) and high oxidizing conditions. A simple configuration using tubesheet (metallic and ceramic tubes) was dismissed due to thermal constraints, junctions' feasibility and ceramic fragility.

Technip and IFP Energies nouvelles have worked on a new concept, using a hybrid solution: at the bottom of the tube, a concrete structure ensures the sheath support and a high temperature resistance. The main upper section of the sheaths, at lower temperature, can be made of metal (hybrid concrete-metal concept). This solution has the advantage of supporting the high flue gas temperature at the chimney inlet thanks to the refractory concrete, but avoids the supporting and thermal inertia problems that a complete concrete filling may have caused. The metallic tubes for the upper part can be made in 602CA with regard to environmental conditions.

The bayonet tube design ensures a continuous heating during the endothermic conversion of methane and steam into syngas. The proper balance between heating and reaction allows the tube temperature to remain below the maximum acceptable value (around $1000^{\circ} \mathrm{C}$ ) despite the very high flue gas temperature (around $1300^{\circ} \mathrm{C}$ ).

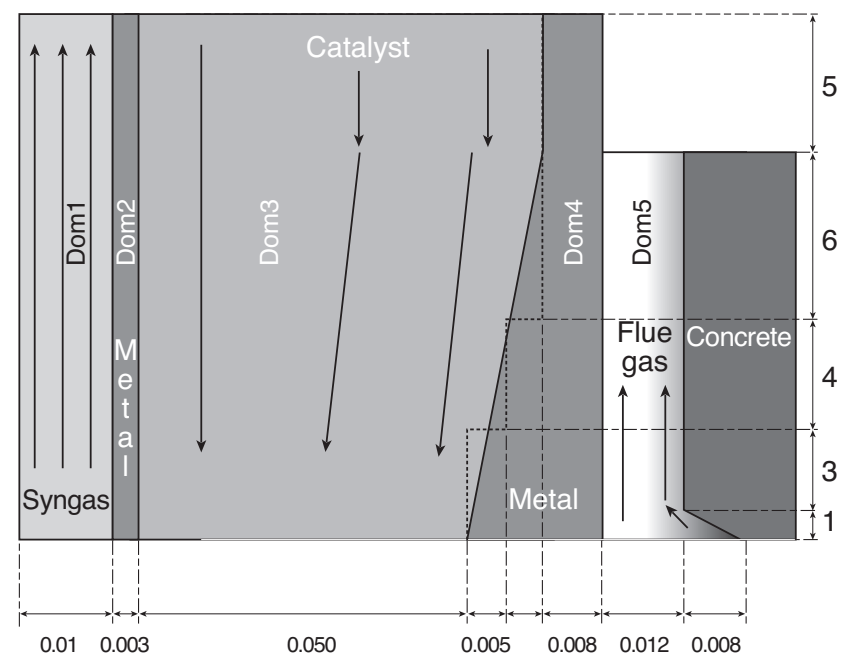

Figure 9

SMR reactor tube geometry. 


\subsection{SMR Reactor Modelling}

The objective of the simulator is to help the SMR tubes design in order to guarantee that the heat transfer from hot flue gas towards the SMR reaction section is high enough without leading to very high metal temperatures causing damage of the tube.

Because the SMR process is made of a bundle of identical SMR reactor tubes, only one tube has been simulated. The main tube geometry that has been used in the simulation is presented in Figure 9. The simulated part of the SMR reactor focuses on the tube section that includes the catalyst section plus the heating sections. On this figure it can be easily seen that the simulator takes 5 domains into account:

- Dom1: the internal bayonet channel ("syngas" in the centre);

- Dom2: the wall between the internal bayonet channel and the SMR catalyst ("Metal");

- Dom3: the SMR catalytic bed for SMR reactions;

- Dom4: the external wall of the overall tube ("Metal");

- Dom5: the flue gas that heats up the tube.

The purpose of the inner tube of the bayonet is to heat the catalyst: no chemical reactions take place in that tube. The wall between the inner canal and the catalyst conducts heat from the produced syngas to the SMR catalytic bed. To be realistic, the simulator includes the chemical reactions, the gas temperature and the hydrodynamics in the catalytic bed. The components taken into account are respectively $\mathrm{H}_{2}, \mathrm{H}_{2} \mathrm{O}, \mathrm{CO}, \mathrm{CO}_{2}, \mathrm{CH}_{4}$ and $\mathrm{C}_{2} \mathrm{H}_{6}$. The chemical reactions are standard shift reaction, steam methane reforming and steam ethane reforming. Because we are using reverse kinetics, chemical concentrations converge towards the

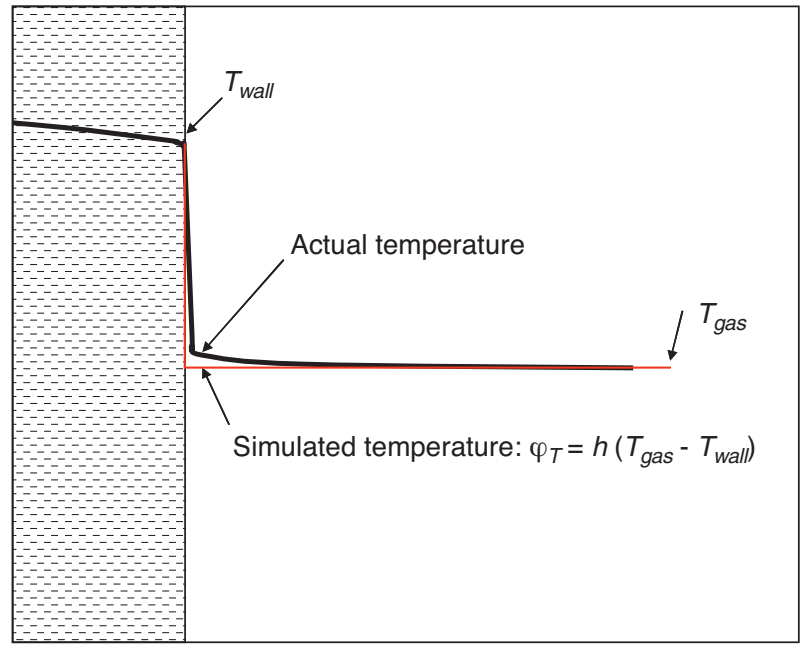

Figure 10

Standard gas-solid heat transfer model. thermodynamics equilibrium but never reach it completely. Chemical kinetics has been previously calculated to match actual reforming reactors in another simulator designed for the purpose [9].

The metallic wall surrounding the catalytic bed is in contact with the very hot flue gas. This flue gas heats the metallic wall that conducts heating energy to the SMR catalytic bed. Because SMR performances are closely connected to the energy provided for the chemical reactions, the modelling of this heating has been performed with great care especially because the flue gas flow is highly turbulent. Hence we use a heat flux calculation that includes a temperature jump across the gas-wall interface. This temperature jump models the actual temperature jump that exists through the thin limit layer along the wall (Fig. 10).

Figure 10 shows the way the heat transfer is simulated. This is a common way to solve this problem but the true difficulty is to define the " $h$ " to calculate the heat flux $\varphi_{T}$. For this simulator, we used the " $h$ " values given by the GRETh [10]. Because these values are very deterministic for the performances of the SMR reactor, we also checked these values with simulations under Fluent and Comsol MP.

The SMR simulator has been used to help to define the design and the operating conditions of the SMR reactor. However most of the geometry variables have to be consistent with commercial equipment which limits the freedom to optimise the reactor size. For example, the radius of the bayonet central tube is given by the manufacturer because, due to fabrication constraints for welded tubes and strength given by its own weight, the minimum internal diameter for the tube is fixed at $30 \mathrm{~mm}$.

The main degrees of freedom are the tube length and the space opened for the flue gas flow under the following main constraints: a $900^{\circ} \mathrm{C}$ syngas temperature at the catalytic bed exit, injected flue gas temperature not exceeding $1300^{\circ} \mathrm{C}$ and the wall temperature compatible with the material limits.

The simulator optimisation result shows that the section of the tube in contact with the flue gas should be $14 \mathrm{~m}$ in length to ensure the required heat transfer from the flue gas to the syngas. The space for the flue gas flow has been limited in radius to induce a high flue gas velocity necessary to achieve a high heat transfer. This space is enlarged at the entrance to reduce the flue gas velocity at that point and hence reduce the heat transfer. In the absence of this enlargement, the metallic wall would have to withstand too high a temperature. This results in lowering of the wall temperature at bottom part of the bayonet.

According to the simulator, the flue gas inlet temperature should be equal to $1293^{\circ} \mathrm{C}$ to provide enough heating to the SMR and the flue gas temperature at the upper exit is closed to $660^{\circ} \mathrm{C}$. This temperature is in the good range to be directed outwards the reactor. The simulated SMR temperature complies with the expected $900^{\circ} \mathrm{C}$. Hence the syngas presents a 
TABLE 2

Syngas composition

\begin{tabular}{c|c|c}
\hline Components & Composition (\%) & Dry composition \\
\hline $\mathrm{H}_{2}$ & 49.8 & 72.2 \\
\hline $\mathrm{H}_{2} \mathrm{O}$ & 31.0 & 0 \\
\hline $\mathrm{CO}$ & 11.0 & 16.0 \\
\hline $\mathrm{CO}_{2}$ & 5.1 & 7.3 \\
\hline $\mathrm{CH}_{4}$ & 3.1 & 4.5 \\
\hline
\end{tabular}

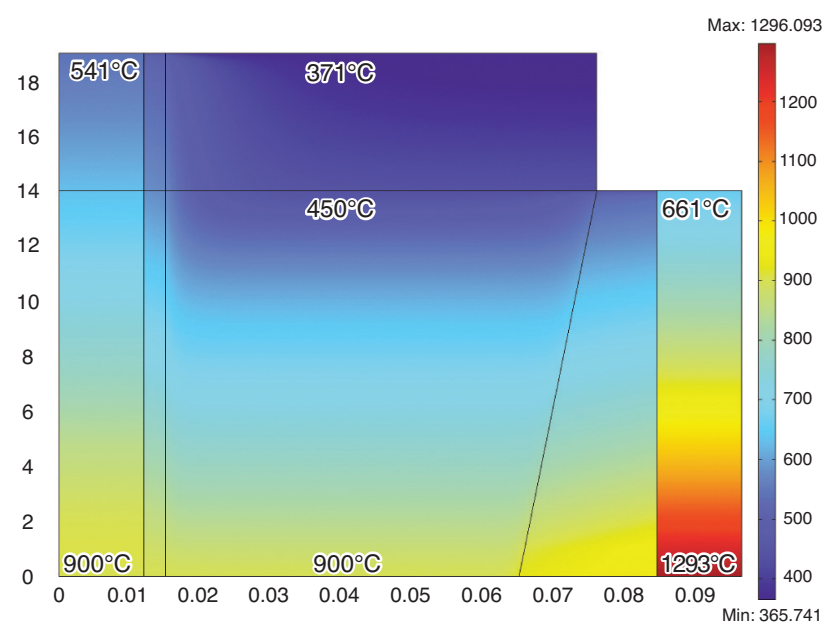

Figure 11

Temperature map in the SMR reactor.

high $\mathrm{H}_{2}$ and $\mathrm{CO}_{2}$ content as it is presented below (Tab. 2). The conversion of the $\mathrm{CH}_{4}$ is not full because it is limited by the thermodynamic equilibrium.

The temperature map obtained with Comsol MP software is presented in Figure 11. Heat flux estimation shows that $1 / 4$ to $1 / 3$ of the energy required for the SMR reactions comes from the syngas and the rest from the flue gas.

To help understanding the temperature map, Figure 12 presents the radial temperature profile at the top of the reactor. The temperature in the gases is constant and exhibits a huge jump when crossing the interface between the gases and the walls. The feed temperature is $371^{\circ} \mathrm{C}$ which is rather low compared to the objective of the SMR at $900^{\circ} \mathrm{C}$.

Figure 13 shows the same profile located at the bottom of the reactor. The temperature of the syngas is at $900^{\circ} \mathrm{C}$ both in the SMR section and in the syngas section which is the exact required temperature for the SMR equilibrium. The temperature jump in the thin gas layer along the metallic wall is in the range of $330^{\circ} \mathrm{C}$ (from $960^{\circ} \mathrm{C}$ to $1293^{\circ} \mathrm{C}$ ). We can notice that the metallic wall is at $960^{\circ} \mathrm{C}$ which is in good agreement

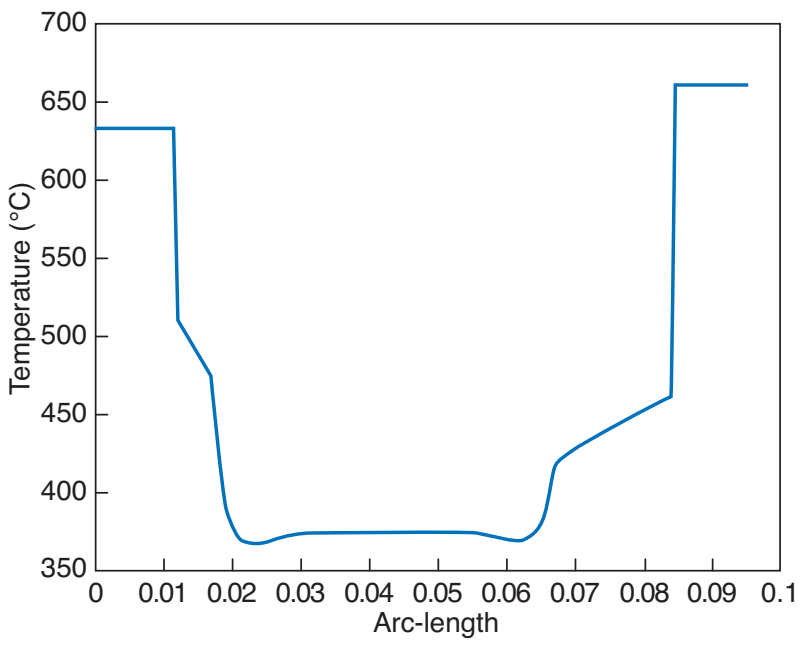

Figure 12

Temperature profile at the top of the SMR reactor.

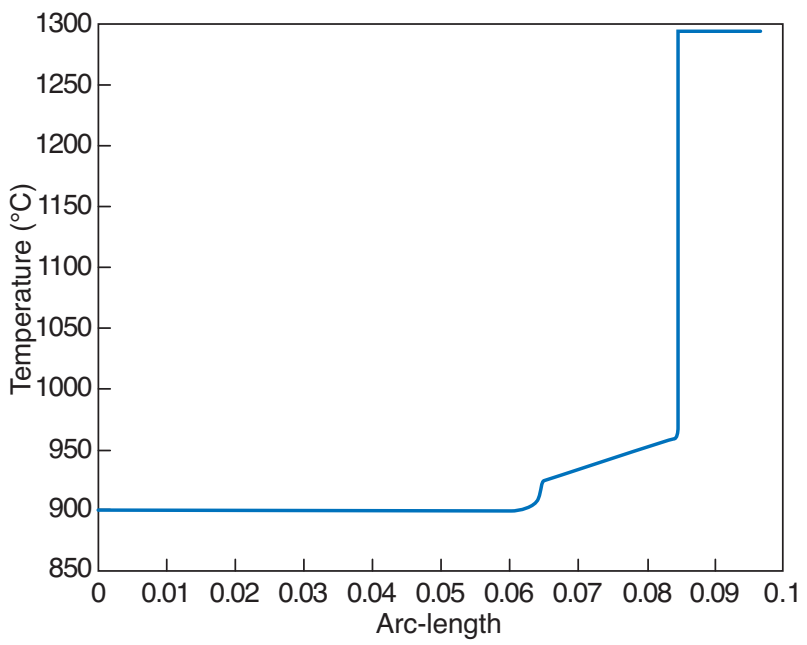

Figure 13

Temperature profile at the bottom of the SMR reactor.

with the specified max temperature that can stand this metallic wall and that the flue gas temperature at the entrance is below $1300^{\circ} \mathrm{C}$, as expected.

As a result, according to the simulator, with 320 tubes of 14 meters in length for the reactive section plus 5 meters for heat exchange purpose, it is possible to reach the expected conversion: the SMR temperature can reach the expected value of $900^{\circ} \mathrm{C}$ to guarantee a high conversion. The resulting hydrogen concentration in dry syngas is more than $72 \%$ vol.

\subsection{Mechanical Sizing}

Numerical simulations using finite elements analysis have been carried out by Technip to optimize the mechanical 
sizing and design of the reactor. The reactor diameter has been determined with regard to the tubes layout. Two main criteria have been considered to implant the tubes:

- an operator accessibility to each tube, for checking flanges for example;

- each tube should be capable of independently dismantled.

The considered material of the reactor wall and support is P355GH. The reactor has been defined to match the design process conditions in terms of pressure (of around 5 bara) and temperature (of around $400^{\circ} \mathrm{C}$ behind the refractory). Furthermore, the ability of the top head to withstand the tubes bundle weight has been checked by Finite Element Analysis. Calculations have been done with ANSYS software to obtain the deformed shape of the top head and the Von Mises stresses maps, as shown in Figure 14.

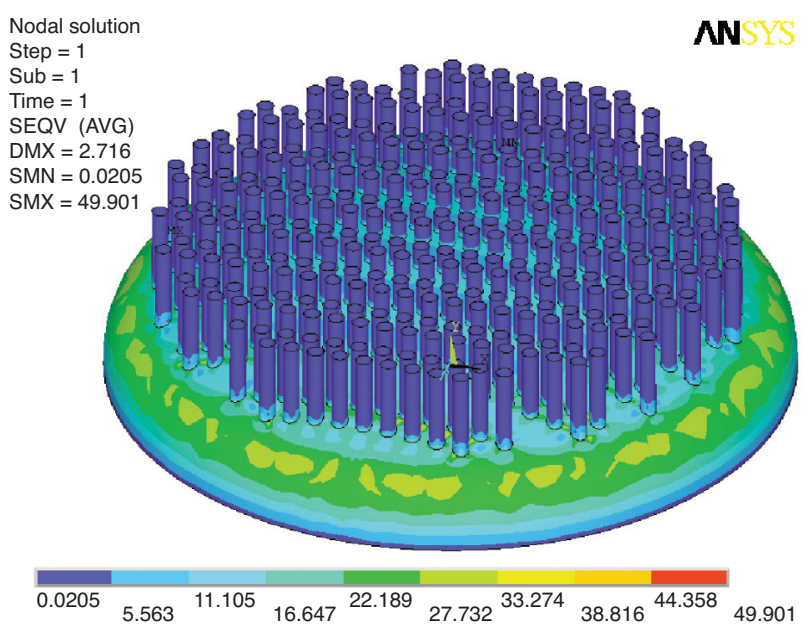

Case with no internal pressure

Figure 14

Von Mises stresses (MPa).

\subsection{Catalyst Loading}

\subsubsection{Loading Issues}

The catalyst loading in the tubes is crucial to enable a long and effective operation. Indeed, any loading discrepancy or unevenness leads to a deviation in heating balance, with serious consequences in material damaging and tubes lifetime. A reliable loading method is considered as acceptable when the following criteria are fulfilled:

- the flow distribution is kept uniform between each tube. In association with a proper flue gas distribution, it ensures a balanced heating of each tube, a reasonable overall conversion and a reasonable tube heating. The general toler- ance on flow variations within the tube is $\pm 2.5 \%$ around the mean value, which corresponds to a pressure drop variation of $\pm 5.0 \%$ around the mean value;

- no bridging/void occurs (Fig. 15). An uneven loading will result in channelling, local tube overheating and possible early tube failure;

- the entire heated section is filled with catalyst with high uniform density;

- no catalyst breakage occurs;

- the catalyst loading operation is fast;

- a minimum number of loading adjustment or tube reloading is required.

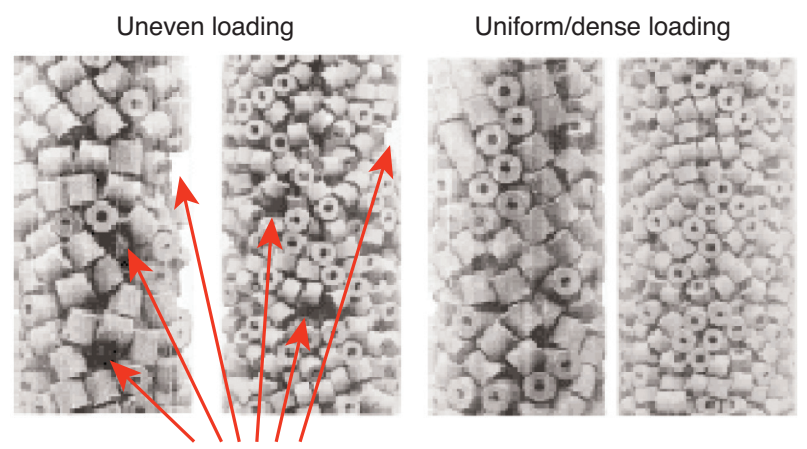

Voids/possible hot spots in operation

Figure 15

Comparison between uneven loading and uniform loading.

\subsubsection{Usual Loading Methods}

In reformer furnaces, the traditional loading of common $10 \mathrm{~cm}$ internal diameter tubes brings into play a sock in association with tube vibration using a hammer, which favours catalyst settling. A proper tube loading can hardly be ensured with these methods and two attempts may be required. Advanced loading procedures and equipments such as those specified in Unidens $^{\mathrm{TM}}$ technology [11] originally developed by Norsk Hydro (Fig. 16) and Spiraload ${ }^{\text {TM }}$ technology [12] from Haldor Topsoe (Fig. 17) are also available and allow more efficient loading (faster and more reliable).

Because of the central recirculation tube and the narrow annular space, the usual loading devices and procedures are not suitable for the HyGenSys reactor bayonet tubes. In addition, the catalyst settlement may differ in bayonet tubes in comparison with simple tubes. Therefore, a new catalyst loading system has been developed. This catalyst loading device ensures the following points:

- prevent catalyst breakage and free fall;

- good catalyst distribution within the tube; 

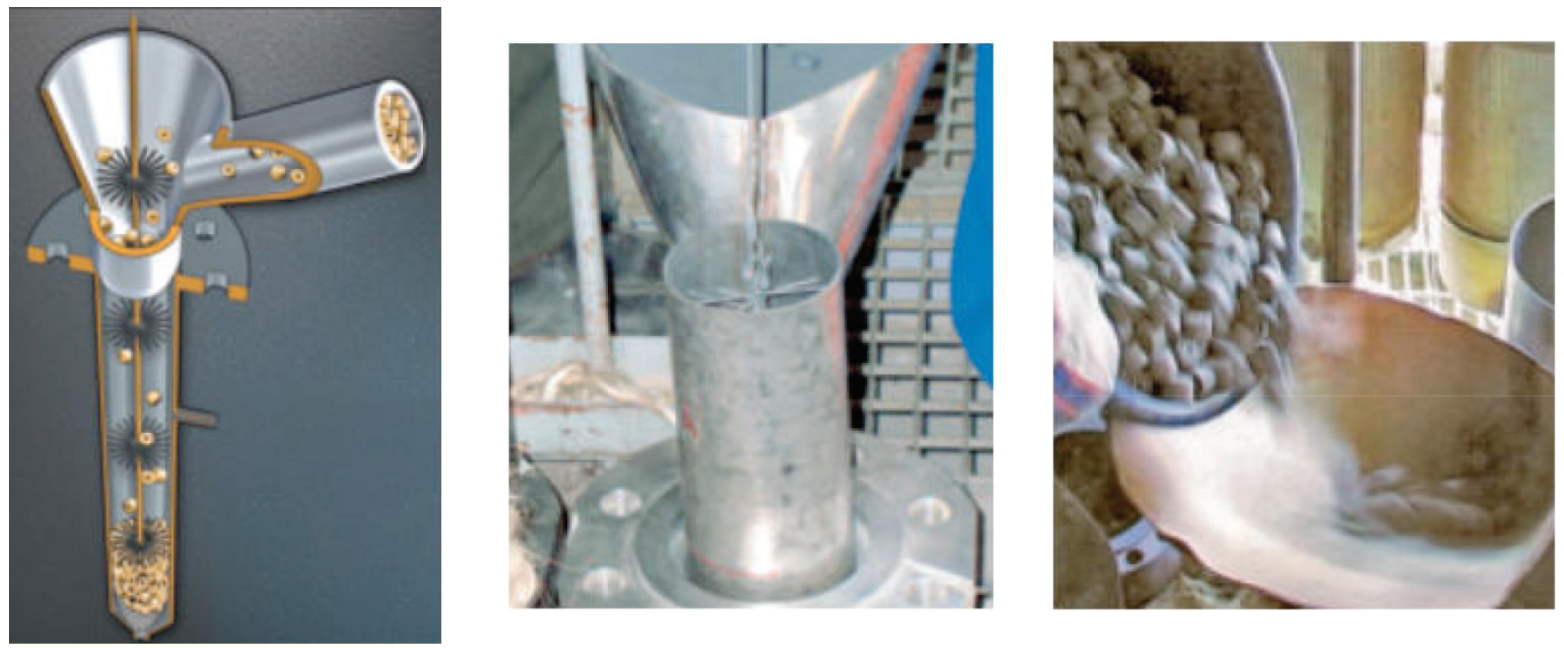

Figure 16

Unidense $^{\mathrm{TM}}$ technology.
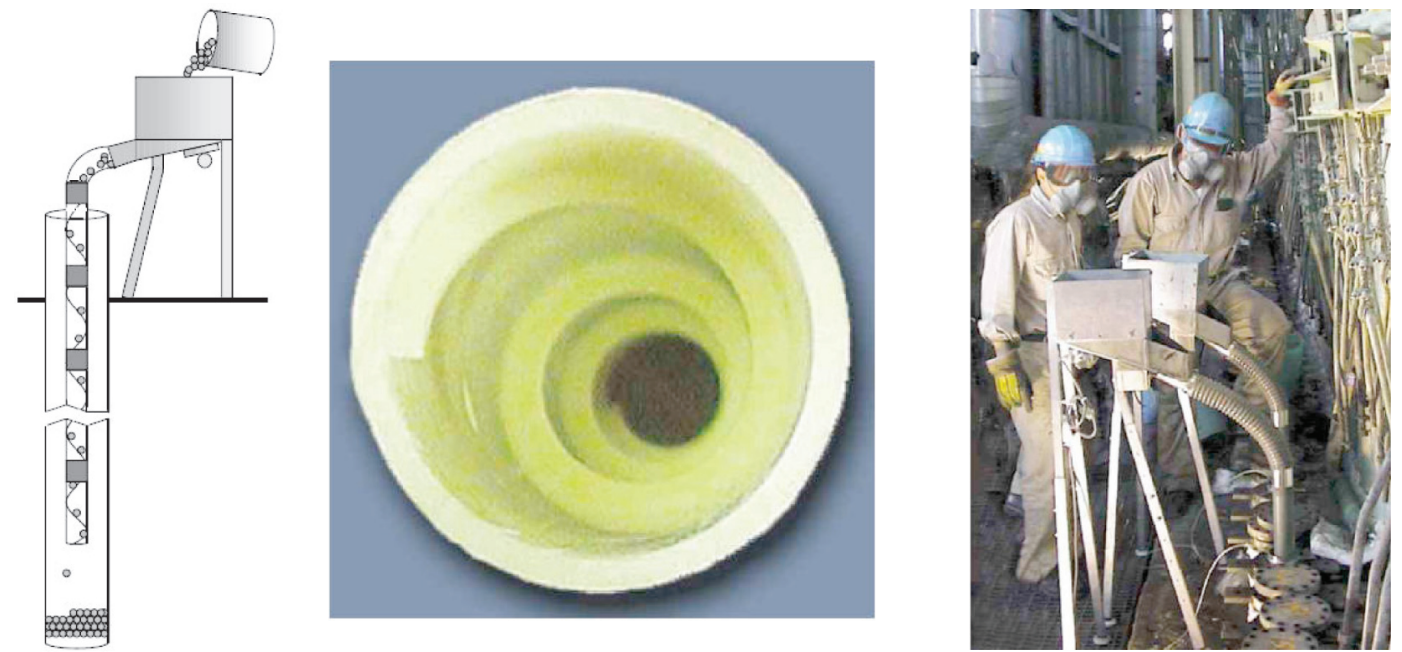

Figure 17

Spiraload ${ }^{\mathrm{TM}}$ technology.

- good catalyst settlement without bridging;

- reasonable loading flowrate;

- no catalyst convey jam within the loading device.

\subsubsection{The Cold Mock-up: Experimental Set-up}

Experimental tests have been done in a dedicated cold mock-up in order to investigate these loading and unloading questions. It consists of a single bayonet tube of $9 \mathrm{~m}$ length and $50 \mathrm{~mm}$ of annular space. The considered commercial catalyst for the experimental tests was BASF SG-9301, which is represented in Figure 18 (BASF courtesy).
The overall tests on the cold mock-up consist in several loading and unloading operations. Once a given amount of catalyst is loaded, measurements are performed in order to evaluate the loading quality (loading density estimation, visual inspection to detect possible catalyst bridging and pressure drop measurement for a given flowrate).

\section{Loading Procedure}

According to the catalyst supplier BASF, the catalyst has been successfully loaded using either sock or Unidense ${ }^{\mathrm{TM}}-$ type loading techniques. The main point is to keep free fall 


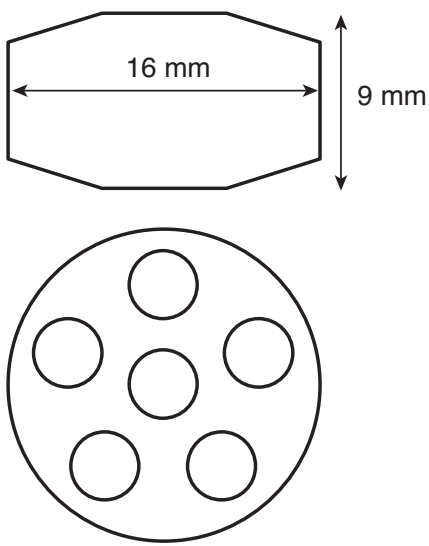

Figure 18

BASF SG-9301 catalyst.

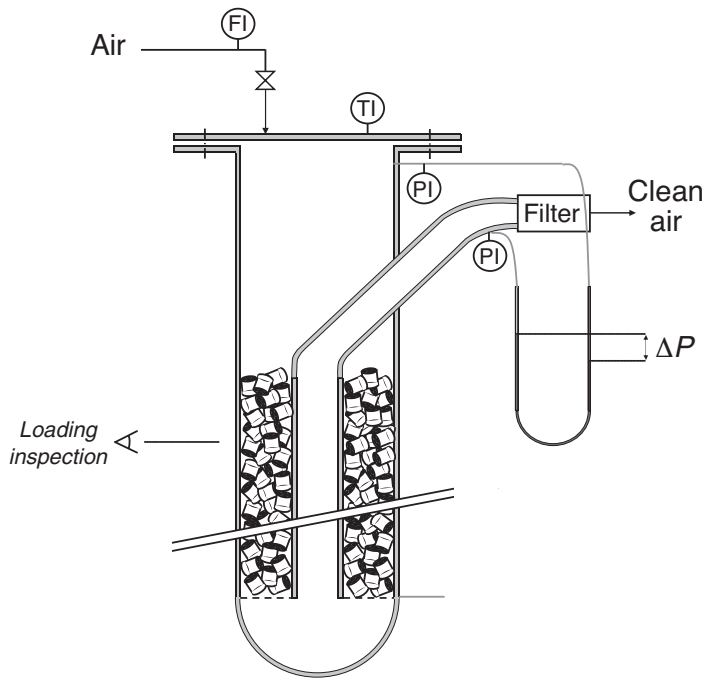

Figure 19

Pressure drop measurement.

height below $50 \mathrm{~cm}$. Therefore, the maximum acceptable pellets velocity when falling on the catalyst bed is around $3 \mathrm{~m} / \mathrm{s}$. The developed loading method relies on assembled loading pipes with relevant internals in order to reduce falling velocity.

\section{Loading Assessment}

Once the tube has been completely loaded, measurements are performed in order to evaluate the loading quality:

- loading density estimation;

- visual inspection to detect possible catalyst bridging;

- pressure drop measurement for a given flowrate.

In order to measure the pressure drop along the catalyst bed, a fixed air flowrate is sent through the column. The air flowrate is adjusted using an automatic valve coupled with a

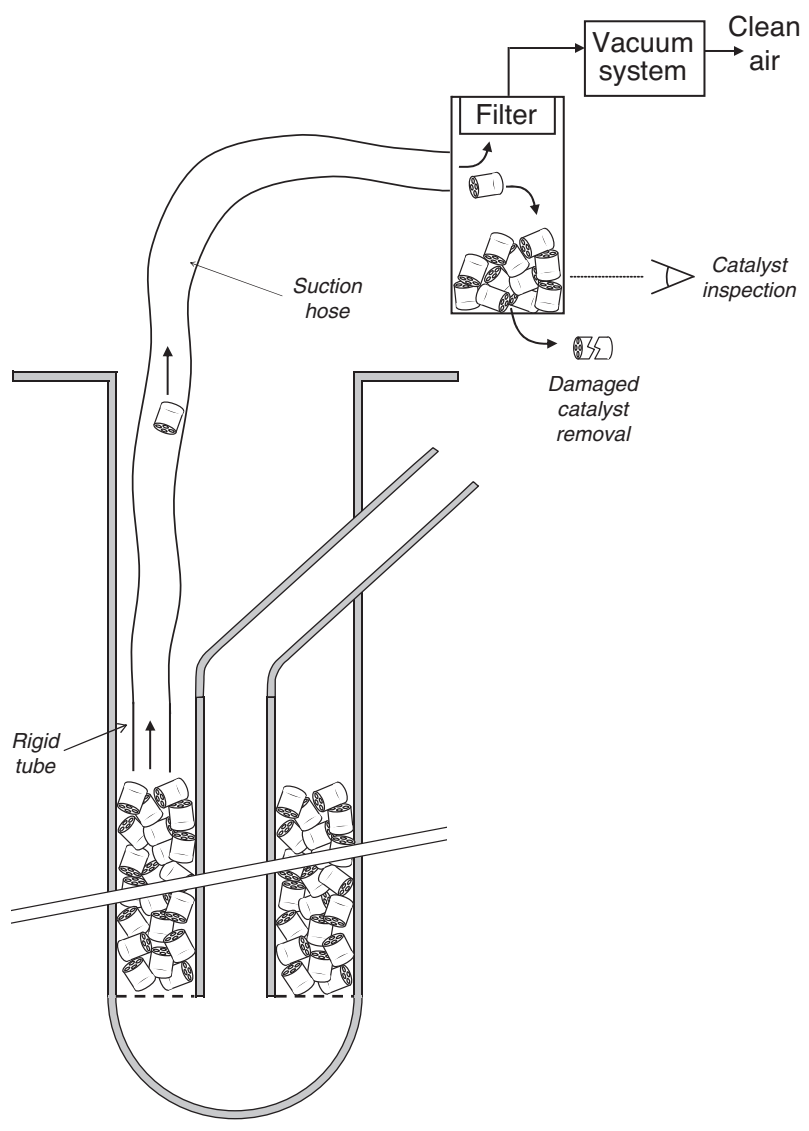

Figure 20

Catalyst unloading.

flow meter. The resulting pressure drop is measured between the inlet of the annular space and the outlet of the bayonet thanks to a U-tube manometer (precision of $10 \mathrm{~mm} \mathrm{H}_{2} \mathrm{O}=$ 1 mbar), as shown in Figure 19.

\section{Unloading Procedure}

Catalyst unloading is achieved using a PIAB vacuum conveyor system and a single suction hose (Fig. 20). A rigid tube is fixed at the end of the hose to make suction of the bottom pellets easier. The depression of the vacuum system is $-0.1 \mathrm{barg}$, with an air flow of about $100 \mathrm{Nm}^{3} / \mathrm{h}$. Pellets are successfully transported into the suction hose at quite high speed and with no blocking inside.

\section{The Cold Mock-up: Experimental Results}

Four loading and unloading tests were carried out with the experimental procedure described above. Firstly, visual inspections of the catalyst bed after loading were conducted. They showed a quite uniform and dense packing, with no void spots, as shown in Figure 21. Secondly, the bed density 


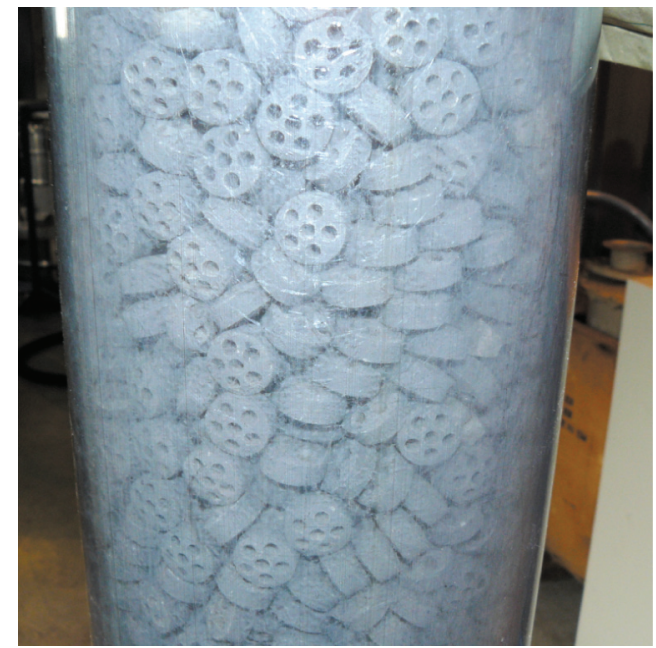

Figure 21

Loaded catalyst bed.

TABLE 3

Catalyst loading results in the cold mock-up

\begin{tabular}{|c|c|c|c|c|}
\hline Test number & 1 & 2 & 3 & 4 \\
\hline Number of pellets (units) & 49550 & 47860 & 47860 & 47100 \\
\hline Pellets mass (kg) & 145 & 140 & 140 & 137.8 \\
\hline Loaded bed height (mm) & 8850 & 8850 & 8850 & 8850 \\
\hline Volume (L) & 139 & 139 & 139 & 139 \\
\hline Bed density $(\mathrm{kg} / \mathrm{L})$ & 1.043 & 1.007 & 1.007 & 0.991 \\
\hline Ambient temperature $\left({ }^{\circ} \mathrm{C}\right)$ & 16 & 18 & 20 & 15,5 \\
\hline Air density $\left(\mathrm{kg} / \mathrm{m}^{3}\right)$ & 1.220 & 1.212 & 1.204 & 1.223 \\
\hline Relative humidity (\%) & 2 & 2 & 2 & 2 \\
\hline Air mass flow rate $(\mathrm{kg} / \mathrm{h})$ & 91.0 & 91.0 & 91.0 & 91.0 \\
\hline Air flow rate $\mathrm{NC}\left(\mathrm{m}^{3} / \mathrm{h}\right)$ & 70 & 70 & 70 & 70 \\
\hline Test air flow rate $\left(\mathrm{m}^{3} / \mathrm{h}\right)$ & 74.6 & 75.1 & 75.6 & 74.4 \\
\hline Velocity $(\mathrm{m} / \mathrm{s})$ & 1.32 & 1.33 & 1.34 & 1.32 \\
\hline$\Delta P\left(\mathrm{~mm} \mathrm{H}_{2} \mathrm{O}\right)$ & 1280 & 1360 & 1405 & 1290 \\
\hline$\Delta P($ mbar $)$ & 125.4 & 133.3 & 137.7 & 126.4 \\
\hline $\begin{array}{c}\Delta P \text { deviation to the mean valuel } \\
\Delta P \text { Mean value }\end{array}$ & $-4.1 \%$ & $+2 \%$ & $+5.3 \%$ & $-3.3 \%$ \\
\hline
\end{tabular}

and the pressure drop were measured. Results are shown in Table 3.

The following conclusions and comments can be drawn:

- deviations of the measured pressure drops with respect to mean value are very close to the $\pm 5 \%$ criteria. Furthermore, the measured deviation includes the experimental error in air flow rate and density. Thus, an acceptable repeatability has been found;
- some broken catalysts were found after each loading/ unloading operation. The presence of broken pellets does not seem to have an evident effect on pressure drop but it increases the bed density;

- visual observations showed a dense packing with a high bed density;

- unloading operation was not an issue but it required long time as well;

- HyGenSys reactor bayonet tubes are able to be loaded and unloaded with commercially available catalyst.

\section{CONCLUSION}

As demonstrated in this article, HyGenSys is a new flexible process that can produce different ratio of hydrogen and power, with or without $\mathrm{CO}_{2}$ capture. To fit those alternative objectives, several flow schemes of HyGenSys have been developed.

The improvement of efficiency and sustainability offered by HyGenSys doesn't rely only on the process itself, but also on the specific reactor-exchanger. This equipment is the heart of the technology. It includes many challenges which allow more efficient energy recovery and therefore less fuel consumption, i.e. less $\mathrm{CO}_{2}$ emissions.

Feasibility of HyGenSys has been demonstrated by process, chemical engineering, mechanical and material studies that cover many scientific aspects. In particular, those studies included tests of bayonet loading and unloading with steam reforming catalyst. The results presented in this article confirm that HyGenSys aims at playing a role among future sustainable process for hydrogen and energy production.

\section{ACKNOWLEDGMENTS}

The authors thank and acknowledge the European Commission (project No. 019972) and every one of the 28 partners [13] in the consortium and especially to BP, NTUA, Technip and Siemens.

\section{REFERENCES}

1 Rojey A., Minkkinen A., Arlie J.P., Lebas E. (2003) Combined Production of Hydrogen Clean Power and Quality Fuels, DGMK-Conference, Innovation in the Manufacture and Use of Hydrogen Proceedings, pp. 102-114.

2 Giroudière F. (2009) CACHET-Hydrogen Generation System (HyGenSys) presentation, European Conference on CCS Research, Development and Demonstration, public workshop Oslo, 2009-02-11.

3 Giroudière F., Ambrosino J.L., Fischer B., Pavone D., SanzGarcia E., Le Gall A., Soutif E. (2009) Vleeming-HyGenSys: a new process for production with pre-combustion $\mathrm{CO}_{2}$, Carbon Dioxide Capture for Storage in Deep Geological Formations, Eide L.I. (ed.), Vol. 3, CPL Press. 
4 Beavis R. (2009) The CACHET Project, 2009 Carbon Dioxide Capture for Storage in Deep Geological Formations, Eide L.I. (ed.), Vol. 3, CPL Press.

5 Dybkjaer I., Winter Madsen S. (2004) Compact hydrogen plants, Hydroc. Eng. 9, 11, 23-25.

6 Giroudière F. et al. (2009) WO 2009/024664 A1.

7 Grablke H.J. (2002) Carburarization, carbide formation, metal dusting, coking, Materiali in Technology 36, 6 .

8 Jones R.T., Maumert K.L. (2001) Metal dusting-an overview of current literature, Corrosion Nace Conference 2001, paper 01372.

9 Johansen T., Raghuraman K.S., Hackett L.A. (1992) Trends in hydrogen plant design, Hydrocarbon Processing, pp. 119-127, Aug. 1992.
10 GRETh Groupement pour la Recherche sur Échangeurs Thermiques, Manuel Technique, août 2004.

11 Unidense Catalyst Loading for Steam Reformers (2008) Johnson Matthey commercial brochure.

12 Spiraload Technology (2008) Haldor Topsoe commercial brochure.

13 Project CACHET partners: www.cachetco2.eu/partners.html.

Final manuscript received in November 2009

Published online in September 2010 or distributed for profit or commercial advantage and that copies bear this notice and the full citation on the first page. Copyrights for components of this work owned by others than IFP Energies nouvelles must be honored. Abstracting with credit is permitted. To copy otherwise, to republish, to post on servers, or to redistribute to lists, requires prior specific permission and/or a fee: Request permission from Documentation, IFP Energies nouvelles, fax. +33147527078, or revueogst@ifpenergiesnouvelles.fr. 